\title{
CORRESPONDENCE
}

Waiting time for urgent appointments Jean Golding PHD

Should we be screening for cervical cancer or breast cancer?

Muriel E Purkiss, MFCM

Methicillin resistant Staphylococcus aureus E M Cooke, FRCPATH, and R R Marples, FRCPATH.

The unremitting burden on carers $M$ Warren, FRCP.

Snoring as a risk factor for ischaemic heart disease and stroke in men

PYates, MRCP.

Association between liberalisation of

Scotland's liquor licensing laws and admissions for self poisoning

A Lawson, FRCP, and others

Manpower

A Morgan, FRCP, and others
Neurological and neurosurgical approaches in the management of malignant brain tumours

Dialysis arthropathy: amyloid or iron?

370 R Ahmad, MB, and others ...

Day surgery: does it add to or replace inpatient surgery?

371 B Hogbin, FRCS .................................. sulphasalarine for rheumatoid arthritis

M Greaves, MRCPATH

The debasing of medicine in the Soviet Union

G A Low-Beer, FRCPSYCH ......................

371 The increase in molluscum contagiosum

M A Waugh, MB .

Prognosis for infants born at 23 to 28 weeks' gestation

A Watkins, FRACP...

A new health region for London?

372 N Kirkham, MRCPATH
How much should private medicine cost?

M G Wright, MRCP

372 Death in the clouds

F S Preston, FFOM

372 Vaccine related poliomyelitis in

non-immunised relatives and household

contacts

373

A Nicoll, MRCP

Correction Association between liberalisation of Scotland's liquor licensing laws and admissions for self poisoning (Lockhart and Baron)

Drug points Alveolitis and haemolytic anaemia induced by azapropazone (A R Morton and others; R D Montgomery and R G Babb; C R Swinburn); Membranous glomerulopathy associated with carbemazepine (L D Hordon and J H Turney); Beware congesting nasa decongestants (D Burley); Pharyngeal blistering with combined inhaler therapy (A S High)

Because we receive many more letters than we have room to publish we may shorten those that we do publish to allow readers as wide a selection as possible. In particular, when we receive several letters on the same topic we reserve the right to abridge individual letters. Our usual policy is to reserve our correspondence columns for letters commenting on issues discussed recently (within six weeks) in the BMF.

Letters critical of a paper may be sent to the authors of the paper so that their reply may appear in the same issue.

We may also forward letters that we decide not to publish to the authors of the paper on which they comment.

Letters should not exceed 400 words and should be typed double spaced and signed by all authors, who should include their main degree.

\section{Waiting time for urgent appointments}

SIR,-The case histories described by Dr Anne McPherson (10 January, p 115) gave much food for thought. They brought to mind the recent history of a relative of mine. She had noticed an unusual looking spot on her thigh and had gone to her general practitioner requesting a referral Although her GP agreed to do this no appointment letter was forthcoming and after four weeks she rang the practice to ask what had happened. There was no record of the GP having written to the hospital, nor was there any record in her notes that she had been seen on that date. Over the phone the GP asked that she go once again to see her, and this time she did indeed refer her to hospital with a suspected malignant melanoma. I should add that my relative had mentioned that there was a family history of this condition.

The urgent appointment requested was for five weeks later. The dermatologist did not believe that the spot was malignant at all but after insistence from my relative removed the small tumour. A follow up appointment was made for her in a further four weeks. She had the clear impression that she was looked on as rather neurotic, belligerent, and demanding. Certainly it is unlikely that action would have been taken without her insisting on it.

At her follow up appointment four weeks later she was told that she had indeed had a malignant melanoma (the dermatologist was very apologetic for not having regarded it as such) and suddenly it was panic stations: she was in hospital the next day for an extensive excision.

There are several points in this case history: the delay with the general practitioner and failure to act on a potentially lethal condition, and a lack of communication within the hospital. Surely the tissue had been examined fairly soon after the excision of the original melanoma, and surely the pathologist had realised that this was a malignant melanoma (indeed his report said so). Should he not have insisted that action be taken straight away?

One of the features of this, my first brush with treatment for potential malignancies, lies in the general lack of comparable statistics. Most of my epidemiological work has been done in perinatal medicine, where every hospital and district is aware of its own perinatal mortality rate and, indeed, is aware of any maternal deaths that may occur. Should it not be feasible also to produce case survival rates for malignancies for residents of each district? Although the type of league table that is produced for perinatal mortality has certain disadvantages, nevertheless it focuses the attention of

Should we be screening for cervical cancer or breast cancer?

SIR,-Health authorities are poised to commit large resources to cervical cytology screening programmes of a thoroughness not previously known in Britain. Emphasis is being laid on calling women

Deaths from carcinoma of the cervix uteri and of the breast by age among residents of Tower Hamlets

\begin{tabular}{lllrrrr}
\hline & Age: & $<35$ & $35-54$ & $55-74$ & $\geqslant 75$ & Total \\
\hline 1985 & Cervix & 0 & 1 & 4 & 1 & 6 \\
& Breast & 1 & 11 & 14 & 12 & 38 \\
1984 & Cervix & 0 & 1 & 5 & 1 & 7 \\
& Breast & 1 & 1 & 14 & 12 & 28 \\
1983 & Cervix & 0 & 1 & 2 & 0 & 3 \\
& Breast & 0 & 4 & 20 & 12 & 36 \\
1982 & Cervix & 0 & 4 & 3 & 0 & 7 \\
& Breast & 0 & 9 & 13 & 16 & 38 \\
1981 & Cervix & 1 & 2 & 1 & 1 & 5 \\
& Breast & 0 & 4 & 17 & 13 & 34 \\
1980 & Cervix & 0 & 4 & 4 & 1 & 9 \\
& Breast & 0 & 7 & 11 & 16 & 34 \\
& & &
\end{tabular}

Source SD25 OPCS. health managers, politicians, and health workers on ways in which the situation could be improved. Without such feedback on survival and mortality from cancer there is little obvious advantage to the clinician in improving his efficiency and speeding up his service. Would it not be possible to use theo National Cancer Registry to produce district based $\overrightarrow{\vec{F}}$ survival figures for the various common treatable 3 cancers so that each district has a baseline from which it can try to improve?

\section{JEAN GOLDING}

Department of Child Health,

University of Bristol

Bristol BS2 8B J from the age of 20. Sume wish to screen evenf younger women if they are sexually active.

However, is it not likely that the epidemiology of? the disease will change because of the acquired immune deficiency syndrome (AIDS)? Occlusive methods of contraception and a reduction in casuakw sexual experience would reduce both AIDS trans-0 mission and cervical carcinoma. The benefit of ano extensive screening programme will therefore be reduced. Efforts must be made to find oldere women who have never had a cervical smear and to establish efficient follow up of abnormal smears, but the balance of resources that would have beend committed to a wide cervical screening programme? might be better applied to screening for breasi cancer. One district's mortality experience mirrors the national situation (table).

Department of Community Medicine,

Department of Community Medici London E1 1BB
MURIEL PURKIS於 